\title{
Professional master program: Preparing the nurse of the future
}

\author{
Mestrado profissional: preparando o enfermeiro do futuro \\ Maestría profesional: Preparando al enfermero del futuro
}

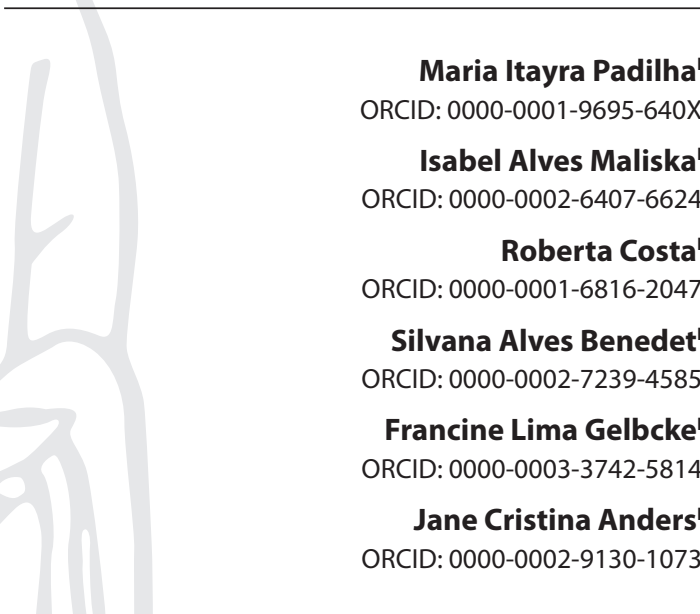

'Universidade Federal de Santa Catarina. Florianópolis, Santa Catarina, Brazil.

How to cite this article:

Padilha MI, Maliska IA, Costa R, Benedet SA, Gelbcke FL, Anders JC. Professional master program: Preparing the nurse of the future. Rev Bras Enferm. 2020;73(Suppl 5):e20200007. doi: http://dx.doi.org/10.1590/0034-7167-2020-0007

\section{Corresponding author:}

Maria Itayra Padilha

E-mail: itayra.padilha@ufsc.br

EDITOR IN CHIEF: Dulce Barbosa ASSOCIATE EDITOR: Antonio José de Almeida Filho

Submission: $04-02-2020$

Approval: 06-22-2020

\section{ABSTRACT}

Objective: Analyze the results of knowledge production from a graduate program for master's degree in nursing. Method: This is a qualitative retrospective documentary study. Data were collected from the university library repository and the program website. In total, 83 dissertations were found, analyzed and arranged into five groups: worker's health, care management, systematization of nursing care, health education, and nursing care. Results: The results indicate good practices such as manuals, guides, protocols, software, and products for systematization of care. They indicate concern about changing the reality with care practices and interventions, health education and continuing education. Final considerations: This study showed student commitment to the fields of practice when choosing the project theme. Students presented an intention to improve care, management, education and research, in the various dimensions of the profession.

Descriptors: Graduate Program in Nursing; Scientific Research and Technological Development; Nursing; Nursing Education; Education.

\section{RESUMO}

Objetivo: Analisar os resultados da produção de conhecimento de um Programa de PósGraduação em Enfermagem, na modalidade mestrado profissional. Método: Pesquisa documental, retrospectiva, com abordagem qualitativa. A coleta de dados ocorreu no repositório da biblioteca universitária e no site do Programa. Foram encontradas 83 dissertações, analisadas e categorizadas em cinco temas: saúde do trabalhador, gestão, sistematização da assistência de enfermagem, educação em saúde e cuidados de enfermagem. Resultados: Os resultados apontam indicativos de boas práticas, como manuais, guias, protocolos, software, bem como produtos voltados à sistematização da assistência. Indicam preocupação em mudar a realidade com práticas e intervenções assistenciais, educação em saúde e educação permanente. Considerações finais: Constata-se o comprometimento dos estudantes com os campos da prática em que atuam, na escolha de tema de projeto. Verifica-se a intenção em melhorar o cuidado, a gestão, a educação e a pesquisa nas várias dimensões do fazer da profissão. Descritores: Educação de Pós-Graduação em Enfermagem; Pesquisa Científica e Desenvolvimento Tecnológico; Enfermagem; Educação em Enfermagem, Educação.

\section{RESUMEN}

Objetivo: Analizar los resultados de la producción de conocimiento de un programa de posgrado en enfermería, modalidad maestría profesional. Método: Investigación documental, retrospectiva con abordaje cualitativo. Datos recolectados en repositorio de la biblioteca universitaria y en el sitio del programa. Fueron halladas 83 disertaciones, analizadas y categorizadas en cinco temas: salud del trabajador, gestión, sistematización de la atención de enfermería, educación en salud y atención de enfermería. Resultados: Los resultados sugieren buenas prácticas, como manuales, guías, protocolos, software, así como productos orientados a la sistematización de la atención. Indican preocupación por cambiar la realidad con prácticas e intervenciones asistenciales, educación en salud y capacitación continua. Consideraciones finales: Se constata el compromiso de los estudiantes con las áreas de la práctica donde actúan eligiendo el tema del proyecto. Se verifica intención de mejorar la atención, la gestión, la educación y la investigación en las variadas dimensiones del que hacer de la profesión.

Descriptores: Educación de Posgrado en Enfermería; Investigación Científica y Desarrollo Tecnológico; Enfermería; Educación en Enfermería; Educación. 


\section{INTRODUCTION}

When talking about the development of graduate programs in Brazil, some important events that happened over the past 70 years must be mentioned, as they contributed to the expansion and predominance of such programs in the fields of science and technology. Scientific communities in institutes, technicalbureaucratic bodies of the government, and the largest universities in the country started to grow and develop an organization requiring better political coordination and association with the process of economic modernization seen in the country and worldwide, ensuring high-level training of human resources(1).

The Brazilian Society for the Advancement of Science (SBPC, in Portuguese) was created in 1948, the Brazilian Center for Research in Physics in 1949, the Coordination for the Improvement of Higher Education Personnel (CAPES) and the Brazilian National Council for Scientific and Technological Development (CNPq) in 1951, as a result of the movement of Brazilian scientists for support and funding of research activities at universities and advanced training of human resources abroad, funded by national and international development institutions, such as the Rockefeller Foundation, Ford and others ${ }^{(2)}$.

In the early 1960s, several facts in the country led to the creation of formal and recognized graduate training, including (i) the Law of Directives and Bases of National Education of 1961, which created graduate education in Brazil; (ii) the University Reform that took place in 1968 and which reinforced an indissolubility between education and research; (iii) growth in the number of student enrollments in higher education; (iv) increase in the number of institutes, implementation of the credit-unit system, and departments considered as units of the system; ( v) the need for professors, and scientists, researchers and technicians for research activities, who are critical for economic and industrial changes in the country; and (vi) increase in the demand for graduate studies ${ }^{(3)}$.

In the same period, the Ministry of Education and Culture (MEC) and the Federal Council of Education (CFE) issued a document with a definition of Graduate Programs (GPs). This document distinguished lato sensu from stricto sensu graduate programs.

Following the Brazilian movement for stricto sensu graduate programs in nursing, the first academic master program was created at the Anna Nery School of Nursing, at the Federal University of Rio de Janeiro (UFRJ) in 1972, in response to the need to qualify nurses for their insertion in the job market, such as educational, research or service institutions. Academic doctoral programs were created ten years later, with the Inter-unit Doctoral program, a result of the efforts of the Nursing Schools of the University of São Paulo (USP), São Paulo and Ribeirão Preto, with a focus on training researchers and expanding scientific nursing studies ${ }^{(2)}$.

Since its creation and in the following decades, a gradual increase was observed in the number of GPs in nursing in different regions of the country, driven by the need for masters and doctors, expansion and appreciation of research groups, increase in the number of nursing journals, more rigorous CAPES evaluation criteria for programs, and intense production of knowledge in the area.

This advance can be explained in numbers. In 2002, the country had 21 GPs and 30 courses including 18 academic master programs
(AMPs), 10 doctoral programs (DPs) and only one professional master program (PMP). In 2007, there were 32 GPs and 42 courses (27 AMPs, 13 DPs and only two PMPs), and in June 2011, 51 GPs and 75 courses (42 AMPs, 24 DPs and 9 PMPs); i.e., an increase of $59.3 \%$ and $78.5 \%$ in the number of programs and courses, respectively. In 2016, 96 GPs, 49 AMPs, 34 DPs and 19 PMPs were available. In general, PMPs had a significant growth in recent years, with a relative growth of $156 \%$, "representing $20.5 \%$ of all approved nursing courses in December 2016, training professionals for the health services in compliance with the 2011-2020 National Post-Doctoral Program (PNPD) and consolidation of the Brazilian Unified Health System (SUS)"(4-5). Stricto sensu GPs produce studies with reviews, questionings, criticisms and discussions about knowledge and practices in health-related areas ${ }^{(6)}$.

The discussions about PMPs started in 1995 with the policy aiming to make GPs more flexible in Brazil, formalized by CAPES in Directive $n^{\circ} 47$, ensuring legal support to professional master programs that had been offered in Brazil, not explicitly in many cases, in the past few years ${ }^{(7)}$. This directive was revoked, as it was replaced with new Directive n 80 , of December 16, 1998, which recognized PMPs and provided conditions for the creation and accreditation of courses. Since then, PMPs have been created by different institutions for various professional areas $^{(8)}$. However, profiles and understandings differ in terms of how a program of this nature should be structured, which is seen even today, as it depends on concrete experiences, expectations and interests of those responsible for creating the program $\mathrm{m}^{(7,9-10)}$.

Professional master programs in nursing are focused on training highly qualified nurses for the job market to produce scientifictechnological knowledge and innovation and develop products and processes that can transform professional practice ${ }^{(2,5,9)}$.

The first PMP in nursing started in 2001, at the Federal University of São Paulo (UNIFESP), with a focus on obstetrics. It had just one group of students, leading to four masters, and ended its activities in 2004. In 2002, the Nursing School of Aurora de Afonso Costa, at Fluminense Federal University (UFF), proposed the second PMP - the first program that effectively became consolidated. In 2006, the PMP in Nursing of the São Paulo State University "Júlio de Mesquita Filho" (UNESP) was created, and only in 2009 the third program in the country was developed, proposed by the Graduate Program in Nursing at the Federal University of Santa Catarina (UFSC), called PMP in Nursing Care Management ${ }^{(2,9)}$.

This program from the UFSC proposes to train nurses for health institutions at different levels of complexity from the public or private network. The course proposes to train nurses with analytical and critical abilities and practice transformation skills, guided by the values and guidelines proposed by the SUS; produce knowledge and innovative proposals for nursing in the dimensions of health care, management and education, promoting an incorporation of science, art and technology to transform nursing practice; and prepare professionals for critical participation in reformulation and/or strengthening of public policies and nursing and health practices to ensure the effectiveness and efficiency of public organizations in the health sector by solving problems and generating innovation ${ }^{(11)}$.

Considering the objectives above, the program has generated dissertations providing good practices such as manuals, guides, 
protocols, software, which, among other materials, have contributed to the Systematization of Nursing Care (SNC). However, no global assessment is available of what has been produced and implemented by the studies of this program and their potential impact on practice. A gap is observed in the exploration of what nurses are producing and the perspectives of studies produced in this GP category ${ }^{(12)}$.

\section{OBJECTIVE}

Analyze the results of knowledge production from a graduate program of master's in nursing.

\section{METHODS}

\section{Ethical aspects}

According to the guidelines proposed by the Ethics Committee on Research with Human Beings (CEPSH), defined in Resolution $466 / 12$ of the National Health Council, this is a documentary study that uses public documents that can be freely accessed by the population, so a prior submission of the study to CEPSH is not required. Also, Resolution 510 of April 7, 2016 states that studies using publicly available information will not be registered or evaluated by the CEP/CONEP system (Research Ethics Committee/National Commission for Research Ethics).

\section{Theoretical and methodological approaches and study design}

This is a qualitative retrospective descriptive documentary study. The use of documents provides objective information in the subjective context where it was built.

\section{Method procedures}

\section{Study site and data source}

The study context was the graduate program in nursing care management, of professional master category, provided by UFSC; the program was created in 2010, focusing on Health Care Management and Nursing, with the following disciplines: Nursing and Health Care Management; Nursing and Health Work Organization and Management; Nursing Care Management in Acute and Chronic Situations in Living, Getting III and Dying Process; Models, Technologies and Innovations for Care in the Human Living Process. It has three fields of expertise $(F E)^{1}$ : Health

1 FE 1. Health and Nursing Technology: Care computerization; Patient safety; SNC; Clinical research; Care protocols; Continuing education; Evidence-based practice; Methods and instruments of care and education; Technological innovation; Health technology assessment. FE 2. Health and Nursing Management and Administration: Care policies and management; People management; Models and processes of care organization; Health and nursing planning; Health and nursing assessment; Care management protocols; Information systems and quality indicators; Product development; SNC. FE 3. Care and the Processes of Living, Being Healthy, Getting III and Dying: Care in the processes of living, getting ill and dying; Safe and humanized care for people and families; SNC; Proposed intervention and innovation in health and nursing care; Health education. and Nursing Technology, Health and Nursing Management and Administration, and Care and the Processes of Living, Being Healthy, Getting III and Dying(11).

\section{Data collection and organization}

Data were collected between April and December 2018 from the UFSC library repository and the GP website considering the 2010-2017 timeframe. The following inclusion criteria were adopted: complete publication available online and/or at the university library. The document sources of the study were 83 dissertations from theses defended in the GP. These sources are considered reliable and original for such analysis ${ }^{(13)}$. All studies were read in full and the following data were extracted and arranged in an instrument produced by the authors: study title, fields of expertise (FE), study objective, methods, study site, participants, results, and final product. Data extraction was performed by three researchers.

\section{Data analysis}

A thematic analysis ${ }^{(14)}$ was used for the assessment of all studies. After all studies were read in detail respecting the proposed assessment stages, five major categories were developed for discussion: worker's health, care management, systematization of nursing care (SNC), health education, and nursing care.

\section{RESULTS}

The results are presented with the details of all categories developed after an assessment of all studies from theses defended in the PMP in Nursing Care Management from 2010 to 2017. Chart 1 shows the general characteristics of these studies $(n=83)$.

Regarding the study methods, most were Convergent care research (31 studies), which is consistent with the PMP adherence to care practice. Qualitative design was also predominant (22 studies), with quantitative approaches used in 11 studies. The remaining (19) were quantitative-qualitative studies, integrative or systematic review, and methodological studies. Regarding study sites, most were conducted in hospital environments ( 74 studies) and the others in maternity hospitals and at homes. Most studies (49) were conducted with the nursing team and only eight with patients and families. The other studies were developed with professionals from the multidisciplinary team, did not involve human beings, or analyzed medical records or other documents. Regarding the results of the dissertations, there is a clear concern of the master program students to improve care, management, education and research itself, in the various dimensions of the profession, due to the emphasis on products such as booklets, protocols, manuals, guidelines, guides seen in 76 studies. Also, the students are clearly concerned about changing reality through care practices and interventions, health education and continuing education, as well as SNC and standard operating procedures (SOP). These materials are intended to benefit the student's institution, health professionals and patients, in the perspective of care, education and/or management. 
Chart 1 - General characteristics of studies from theses defended in the Professional Master Program in Nursing Care Management, Florianópolis, Santa Catarina, Brazil, 2018

\begin{tabular}{|c|c|c|c|c|}
\hline Fields of expertise (FE) & Method & Study context & Subjects & Products \\
\hline \multirow[t]{2}{*}{$\mathrm{FE}^{*} 1-22$} & Quantitative: 12 & General hospital: 74 & Nurses: 20 & $\mathrm{SNC}^{\dagger}: 6$ \\
\hline & Qualitative: 22 & Maternity hospital: 5 & Nursing team: 29 & Protocol: 8 \\
\hline \multirow[t]{2}{*}{$\mathrm{FE}^{*} 2-24$} & Quantitative/ & Home: 4 & Health professionals: 5 & Manual: 2 \\
\hline & Qualitative: 7 & & Patients: 8 & Guidelines: 1 \\
\hline \multirow[t]{7}{*}{$F E^{*} 3-37$} & Methodological study: 3 & & Patients and professionals: 8 & Booklet: 4 \\
\hline & Review: 8 & & Document: 13 & Guide: 18 \\
\hline & Convergent care research: 31 & & & Bundle: 1 \\
\hline & & & & Online course: 1 \\
\hline & & & & Software: 3 \\
\hline & & & & Recommendations: 14 \\
\hline & & & & Educational process: 12 \\
\hline
\end{tabular}

Note: *FE: field of expertise, $+S N C$ : systematization of nursing care.

The five categories obtained in the thematic analysis are presented as follows.

The nursing care category had 35 dissertations. Most of these studies were developed with nursing team professionals seeking reflections about the practice and the development of proper interventions/care. Examples of the results of these dissertations are protocols for companions and patients, care for discomfort and pain management in newborns, care for oncology-hematology patients, and several guides: for prevention and treatment of skin lesions in newborns, for peripheral intravenous therapy for newborns and children, for nursing care to burn injuries in adults, for people with diabetes mellitus in the perioperative period, for intravenous drug care, good practices of nursing care to blood donors with adverse reactions, for pressure injury nursing care, good practices for changing decubitus position of ICU patients, and good practices for the prevention of primary bloodstream infection associated with the use of short-term central venous catheters. Good practices, intervention flowcharts, standard operating procedures, recommendations, and care guidelines were also products generated in this category. These studies were mostly linked with FE 3 (16).

The worker's health category had six studies, which were all developed in a hospital environment with the nursing team. The studies were linked with FEs 2 and 3. Two studies addressed the workload in the hospital environment, one study was a diagnosis of influenza vaccination by nursing professionals, one study analyzed stress of professionals and its impact on the process of care and self-care, one study addressed the prevention of adverse events in inpatient units, and one study was related to the previous one, addressing the development of a prototype program for health event/incident reporting process, consisting of a technological product, like others, such as booklets, protocols, guides. Two situational diagnoses were also performed aiming to propose changes in professional practice.

The category of health education had 13 studies, most related to FE 3. In terms of products and processes resulting from these studies, all dissertations expressed concern about the quality of care and, more specifically, about the subjects receiving care: children, adolescents, adults or the elderly, with the development of manuals, guidelines, booklets and an online course to better guide individuals and their families in terms of self-care after hospital discharge. Regarding continuing education of the nursing team, permanent educational processes were also proposed, as well as a bundle ${ }^{2}$ for the prevention and control of hospital infections in emergency services, and an educational program for the nursing team working in the area of transplantation.

The health care management category had 17 studies linked with all three FEs, but six studies were more particularly related to the nursing work process in different areas. This category had four qualitative studies, one quantitative study and one methodological analysis. All studies were developed in hospitals with nursing professionals as subjects in one of their data collection stages. Regarding the work process, the following themes were studied: personnel dimensioning, turnover of professionals in an adult emergency unit, structure of material and sterilization centers, competencybased performance evaluation for nurses, waste management, management procedures of an ethics committee. As products of these studies, the following was developed: instruments for daily production records of the material center, personnel management indicators of the adult emergency unit, proposal of a professional performance evaluation model, construction and validation of an instrument of management procedures for an ethics committee.

Also regarding management, four studies (two quantitative and two qualitative studies) were focused on patient safety developed in the adult emergency unit, pediatric inpatient unit, intensive care unit, and material and sterilization center. Three research studies involved the nursing team as subjects and one research study, the health team. Two research studies produced safe care recommendations. One resulted in a situational diagnosis of the material center and one presented an instrument to systematize staff shift change, aiming to ensure proper communication between professionals.

Regarding the management of specialized care, seven studies were identified: three qualitative and two quantitative-qualitative studies, one descriptive and one documentary study. All of them were developed in hospitals, medical and surgical clinics, and one in a blood bank. Patients were the subjects in two studies, and the nursing team in the others. The studies addressed the following

2 A bundle is a structured way of improving the processes of care and patient outcomes: a small, straightforward set of evidence-based practices - generally three to five - that, when performed collectively and reliably, have been proven to improve patient outcomes. 
themes: integral care, systematization of staff shift change, records of nursing actions, records of blood transfusion information, and three studies addressed care after hospital discharge, including hospital discharge planning, remote monitoring, health education for continuity of care. These studies resulted in the production of a checklist for staff shift change, blood transfusion record instrument and standard operating procedure, supporting the development of a nursing care instrument, nursing follow-up instrument for patients submitted to stem cell transplantation, guidelines for hospital discharge based on the principle of comprehensiveness, an educational booklet for follow-up of patients with peripheral arterial occlusive disease.

The SNC category had 12 studies, considering the studies whose objectives were: assess the applicability of SNC to nursing practice. Of these, five developed care plans for different types of patients (preoperative, hemodialysis, fetal death, pregnant women with preeclampsia, and for the management of neonatal pain). Two studies addressed the issue of nursing diagnosis and five developed subsidies for the implementation of SNC in the units/institutions of the master students, highlighting the development of a software prototype for the implementation of SNC in the neonatal unit. Studies using convergent care and action research prevailed in this category. Regarding the participants, most studies were developed with nurses, and others collected data from medical records and involved the nursing team as a whole. The studies of this category were linked with FEs 2 and 3.

\section{DISCUSSION}

There is no question about the credibility and importance of PMPs as a complement of stricto sensu graduation training, in contrast to a statement about this new course category ${ }^{(15)}$ that says PMPs would be a "great mistake in the national graduate policy," as it could cause "significant consequences for the future of this level of education," because in this perspective ${ }^{(15)}$, PMPs would undermine the development of research and the achievements of stricto sensu education. This concept gradually changed and today it is clear that, although there are still some points of resistance, PMPs have received more and more confidence and credibility ${ }^{(16)}$.

PMPs created the need for public and expanded debate about issues that were previously limited to the academic environment, presenting a vita activa to the university as the source and destination of this knowledge. "Therefore, the public space is brought up by PMPs as these programs propose to insert social demands in the heart of the university and take to society knowledge that was previously restricted to the academic world"(7).

In nursing, the differences between the academic master and professional master programs become more evident, as in PMPs the professional is a researcher of his practice and, for this reason, training must be oriented to research, whose final study must promote critical reflection about the professional practice, with its results immediately absorbed and transforming this practice ${ }^{(16)}$. A concern about the perspective of the practice was expressed in the studies analyzed, since many of them intended to discuss with peers about the practice and then propose solutions through guides, protocols, manuals, booklets, among other products generated by the master program students. In some studies, the method of convergent care research and action research favored this purpose, reinforcing the concern identified.

A study that summarized knowledge production of the PMP in nursing care management at UFSC between 2013 and 2017 showed that, through applied research, it is possible to strengthen the principles of SUS and advance in nursing research ${ }^{(17)}$.

Then, the question is: to what extent are PMPs different from academic master programs? We believe the most appropriate answer is that PMPs promote stricto sensu professional training for a non-academic market, particularly focused on training to transform the professional practice with an emphasis on management, production or application of knowledge for solving problems or proposing innovation by incorporating the scientific method and updating relevant knowledge ${ }^{(18)}$.

Then, the programs are focused on training nursing professionals for the production of scientific-technological knowledge and innovation for the generation of products and processes that can transform and qualify the professional practice ${ }^{(2)}$. PMPs in nursing have effectively contributed to reducing the distance between the academic world and the labor market, allowing, through numerous technological products, improvements in the most varied areas where nursing professionals are present ${ }^{(17)}$.

Products and processes resulting from studies of the PMP analyzed, such as manuals, guides, protocols and software, were developed to improve the professional nursing practice and make care safer and more organized, guided by models that can be applied to different care environments. These products describe in detail specific care strategies for a given situation, incorporating rules, routines and procedures related to a certain health problem/condition. They help guide the work of the team or a specific professional group and officially record care provided while solving or preventing a problem, in the case of protocols.

The products are expected to bring technological innovations for safer care, enabling appreciation of professional experience. Innovation refers to the generation of new ideas, resulting in studies to improve a service, program, structure, product and/or process. These studies can lead to innovative ways to perform an activity and/or new products, changes in behavior, new cultures at work and new markets ${ }^{(19)}$.

Therefore, with the consolidation of PMPs, technological innovations have been produced, but still centered on hard or soft-hard technologies, as identified in a previous study, which indicated deficit in the production of hard technologies ${ }^{(20)}$.

Studies focused on care showed an interest in systematizing nursing actions to ensure patient safety and improvements in the quality of care. Such concern also includes post-discharge care, showing a broader perspective of professionals beyond the institutional space, aiming to extend care to include preparation for discharge and, against reference in the primary care network, monitoring at home, using health education to promote self-care. Care, as the essence of the profession, is a constant theme in knowledge production and interventions proposed in PMP studies, which is justified by the nature of these programs, indicating convergence between what is produced and the legislation supporting the PMPs ${ }^{(21)}$.

Also in this sense, regarding care management, a nurse's work is expressed in a dialectical relationship between knowing how to manage and knowing how to care, characterized as something 
dynamic that requires the development of both management and care skills ${ }^{(21)}$. It is focused on the micro-level structure, when considering the physical structure, guarantee of physical and human resources, and a methodology and systematization of care, expanding this perspective to the health care network that receives post-discharge patients and which must be equipped for continuity of care, seeking to ensure integral care, as recommended by SUS.

In this proposal, PMPs provide an opportunity to develop new management approaches to nursing care that can go beyond care practices and implement more horizontal models, adopting health education and health promotion as intervention approaches ${ }^{(22)}$.

The nursing work process involves care, management and education, which support the profession's assignments. Study productions reflect such assignments, particularly care and management, and regarding education, the productions address health education, centered on patients, through the development of booklets and manuals, which was also identified in a study that assessed the production of three PMPs in nursing ${ }^{(20)}$. Such production built on the profession's assignments agrees with the concepts of PMPs, which seek to train in order to transform the practice, based on the problems of the practice itself.

Education for the training of professionals in health is seen as a driver of changes as it supports the construction of knowledge and professional action. Then, institutions of higher education, recognized as knowledge producers, must assume the complex assignment of training professionals that are capable to intervene in social needs ${ }^{(23-24)}$.

\section{Study limitations}

Study limitations refer to the fact that no comparative analysis with other PMPs in Latin America was performed; however, when considering the excellence of PMPs in the country, this limitation was irrelevant. Also, the applicability of the technologies resulting from PMPs to nursing care could not be assessed. We understand it could be analyzed in further studies.

\section{Contributions to the areas of nursing, health or public policy}

This study will help evaluate the development of a proposed professional master program and then point out the strengths and weaknesses that a program can have. The experience with each program can guide the view of other courses when considering their specificities. In addition, this study can support the search for new objects and pedagogical and methodological strategies for the development of a professional master program.

\section{FINAL CONSIDERATIONS}

When analyzing the production of knowledge from dissertations of a specific graduate program, the perspective of analysis was expanded to reflect on the professional master programs in nursing in Brazil. In addition, it shows concern and commitment of master program students to their fields of practice, as well as a concern about improving care, management, education and research itself in the various dimensions of the profession. It also shows an interest in changing reality through care practices and interventions, health education and continuing education, as well as SNC and the development of SOPs.

The results of research studies are intended to benefit the institution associated with the master program student, health professionals and patients, whether in care, education and/or management. The program results since its implementation eight years ago have produced good practices such as manuals, guides, protocols, software focused on care systematization, among other aspects.

Concern about the impact of knowledge generated in the PMP on the transformation of professional nursing practice was also observed in the studies. This is a challenge that is in the process of maturing and that may need to be revised in terms of PMP objectives and how they are currently implemented. The production generated in the investigations under the program is expected to change the reality of nurses; however, the material analyzed in this study did not allow an assessment of such impact.

\section{REFERENCES}

1. Santos ALF, Azevedo JML. Postgraduate studies in Brazil, research in education and studies on educational policy: contours of the constitution of an academic field. Rev Bras Educ. 2009;14(42):534-50. doi: 10.1590/S1413-24782009000300010

2. Scochi CGS, Munari DB, Gelbcke FL, Erdmann AL, Gutiérrez MGR, Rodrigues RAP. The Strict Sense Nursing postgraduation in Brazil: advances and perspectives. Rev Bras Enferm. 2013;66(spe):80-9. doi: 10.1590/S0034-71672013000700011

3. Cirani CBS, Campanario MA, Silva HHM. The evolution of stricto sensu post-graduate education in Brazil: exploratory analysis and research proposals. Avaliação. 2015;20(1):163-87. doi: 10.590/S1414-40772015000500011

4. Scochi CGS, Ferreira MA, Gelbcke FL. The year 2017 and the four-yearly evaluation of the Stricto Sensu Graduate Programs: investments and actions to continued progress. Rev Latino-Am Enfermagem. 2017;25:e2995. doi: 10.1590/1518-8345.0000.2995

5. Coordenação de Aperfeiçoamento de Pessoal de Nível Superior. Relatório de avaliação 2013-2016 [Internet]. Quadrienal 2017 [cited 2019 Apr 11]. Available from: https://capes.gov.br/images/stories/download/avaliacao/relatorios-finais-quadrienal-2017/20122017ENFERMAGEM-quadrienal.pdf

6. Agra MAC, Freitas TCS, Caetano JA, Alexandre ACS, Sá GGM, Galindo NNM. Nursing dissertations and theses on the mobile emergency care services: a bibliometric study. Texto Contexto Enferm. 2018;27(1):e3500016. doi: 10.1590/0104-07072018003500016

7. Mamede W, Abbad GS. Educational goals in a professional master's degree in public health: assessment according Bloom's Taxonomy. Educ. Pesqui. 2018;44:e169805. doi: 10.1590/s1678-4634201710169805 
8. Barros EC, Valentim MC, Melo MAA. O debate sobre o mestrado profissional na Capes: trajetória e definições. RBPG. 2005;2(4):124-38. doi: 10.21713/2358-2332.2005.v2.84

9. Scochi CGS, Gelbcke FL, Ferreira MA, Alvarez AM. Professional Master's Degree: potential contribution to Advanced Practice Nursing. Rev Bras Enferm. 2015;68(6):1186-9. doi: 10.1590/0034-7167.2015680626i

10. Quaresma M. Pedagogical issues of the professional master's course: an approach to the subject based on bibliographic analyzes. RBPG. 2014;11(24):461-81. doi: 10.21713/2358-2332.2014.v11.508

11. Programa de Pós-Graduação em Gestão do Cuidado de Enfermagem - Modalidade de Mestrado Profissional [Internet]. 2018 [cited 2019 Jul 20]. Available from: http://mpenf.ufsc.br/

12. Silvino ZR, Santos I. Paradigmatic perspectives of the technological production of Postgraduate Nursing courses: a descriptive study. Online Braz J Nurs. 2013;12:614-6. doi: 10.5935/1676-4285.20134517

13. Padilha MI, Bellaguarda MLR, Nelson S, Maia ARC, Costa R. The use of sources in historical research. Texto Contexto Enferm. 2017;26(4):e2760017. doi: 10.1590/0104-07072017002760017

14. Minayo MCS. Qualitative analysis: theory, steps and reliability. Ciênc Saúde Coletiva. 2012;17(3):621-6. doi: 10.1590/ S1413-81232012000300007

15. Severino AJ. The professional master's program: one more mistake in national policy for post-graduation. Rev Educ PUC-Campinas [Internet]. 2006 [cited 2019 Jul 20];21:9-16. Available from: http://periodicos.puc-campinas.edu.br/seer/index.php/reveducacao/article/ view/204/187

16. André M, Princepe L. The place of research in the Professional Master's Program in Education. Educ Rev. 2017;63:103-17. doi: $10.1590 / 0104-4060.49805$.

17. Souza CJ, Silvino ZR. The production of the professional master's degree in nursing of the Federal University of Santa Catarina, $2013-2016$. Rev Bras Enferm. 2018;71:2751-57. doi: 10.1590/0034-7167-2018-0153

18. Bomfim AM, Vieira V, Deccache-Maia E. Criticism of the professional masters: a reflectionon what would be the most relevant contradictions. Ciên Educ (Bauru). 2018;24(1):245-62. doi: 10.1590/1516-731320180010016

19. Souza ML, Prado ML, Sasso GTM, Martins CR, Monticelli M. A inovação tecnológica e o cuidado de enfermagem. Temperamentvm [Internet].2010 [cited 2019 May 12];11. Available from: http://www.index-f.com/temperamentum/tn11/t7172p.php

20. Munari DB, Parada CMGL, Gelbcke FL, Silvino ZR, Ribeiro LCM, Scochi CGS. Professional Master's degree in nursing: knowledge production and challenges Rev Latino-Am Enfermagem. 2014;22(2):204-10. doi: 10.1590/0104-1169.3242.2403

21. Christovam BP, Porto IS, Oliveira DC. Nursing care management in hospital settings: the building of a construct. Rev Esc Enferm USP. 2012;46(3):734-41. doi: 10.1590/S0080-62342012000300028

22. Santos JLG, Pestana AL, Guerrero P, Meirelles BSH, Erdmann AL. Nurses' practices in the nursing and health care management: integrative review. Rev Bras Enferm. 2013;66(2):257-63. doi: 10.1590/S0034-71672013000200016

23. Figueredo WN, Laitano ADC, Santos VPFA, Dias ACS, Silva GTR, Teixeira GAS. Didactic-pedagogical training in stricto sensu graduate programs in Health Sciences of Federal Universities in the Northeastern region of Brazil. Acta Paul Enferm. 2017;30(5):497-503. doi: 10.1590/1982-0194201700072

24. Freitas, MAO, Demarchi, GSS, Rossit, RAS. Educação Interprofissional na pós-graduação stricto sensu: o olhar dos egressos. Interface (Botucatu). 2018;22:1647-59. doi: 10.1590/1807-57622017.0644 